\title{
O CENTRO DE ENSINO DE 2 GRAU PROFESSOR ANÍSIO TEIXEIRA (1974-1985): NOTAS HISTÓRICAS E PEDAGÓGICAS
}

\author{
Antonio Max Ferreira Costa; José Mateus do Nascimento \\ Programa de Pós Graduação em Educação Profissional (PPGEP-IFRN) \\ DOI: $10.15628 /$ rbept.2018.7274
}

Artigo submetido em mar/2018 e aceito em maio/2018

\begin{abstract}
RESUMO
O presente artigo é um recorte da dissertação de mestrado em educação, desenvolvida e defendida em 2017, no Programa de Pós-Graduação em Educação Profissional, do Instituto Federal de Educação, Ciência e Tecnologia do Rio Grande do Norte (PPGEP-IFRN). Este escrito discorrerá sobre a História do Centro de Ensino de 2oㅡrau Professor Anísio Teixeira, com recorte temporal (1974-1985), objetivando reconstruir a história dessa instituição escolar de referência à época, no que tange a oferta de ensino técnico profissionalizante para os filhos da classe-que-vive-do-trabalho, com cursos na área de Administração e Contabilidade para abastecer o mercado de trabalho da cidade de Natal-RN. Para a construção desse texto, utilizou-se a pesquisa qualitativa com abordagem histórica, tendo por base levantamentos bibliográficos e documentais nos arquivos da Escola, com destaque para a implementação da Lei № 5.692/1971.
\end{abstract}

Palavras-Chave: História. Ensino Técnico Profissionalizante de 2o Grau. Lei № 5.692/1971. Educação Profissional.

\section{THE TEACHING CENTER OF TEACHING OF 2 DEGREE TEACHER ANÍSIO (1974-1985): HISTORICAL AND PEDAGOGICAL NOTES}

\begin{abstract}
This article is a cross-section of the master's thesis in education, developed and defended in 2017, in the Post-Graduation Program in Professional Education, Federal Institute of Education, Science and Technology of Rio Grande do Norte (PPGEP-IFRN). This paper will discuss the History of the Secondary School Professor Anísio Teixeira, with a temporal cut (1974-1985), aiming to reconstruct the history of this school institution of reference at the time, regarding the offer of vocational technical education for the children of the work-life class, with courses in the area of Administration and Accounting to supply the labor market of the city of Natal-RN. For the construction of this text, we used the qualitative research with a historical approach, based on bibliographical and documentary surveys in the archives of the School, highlighting the implementation of Law No. 5,692 / 1971.
\end{abstract}

Keywords: History. Vocational Technical Education of 2nd Degree. Law № 5.692 / 1971. Professional Education. 


\section{INTRODUÇÃO}

Esse artigo é um recorte da dissertação de mestrado em educação, desenvolvida e defendida em 2017, no Programa de Pós-Graduação em Educação Profissional, do Instituto Federal de Educação, Ciência e Tecnologia do Rio Grande do Norte (PPGEP-IFRN).

$O$ texto encontra-se organizado em quatro partes: na primeira parte, será apresentada, a história da fundação do Centro de Ensino de 2ํㅡ Grau Professor Anísio Teixeira (1974-1985), inclusive justificando o porquê do recorte temporal anunciado aqui. Na segunda parte mostra-se o contexto da reforma do ensino técnico profissionalizante por força da Lei № 5.692/1971.

Já na terceira parte, faz-se uma reflexão em torno da materialização da Lei № 5.692/1971, no contexto das práticas pedagógicas e da tendência pedagógica do tecnicismo, que imperava no Centro de Ensino de 20 Grau Professor Anísio Teixeira, todas essas partes do artigo, foram construídas por meio de uma pesquisa qualitativa com abordagem histórica, tendo por base levantamentos bibliográficos e documentais nos arquivos da Escola, com destaque para a implementação da Lei № 5.692/1971. Na quarta e última parte, apresenta-se as considerações finais.

\section{FUNDAÇÃO DO CENTRO DE ENSINO DE 2 GRAU PROFESSOR ANÍSIO TEIXEIRA}

Nos anos de 1971 a 1985, o Ensino Técnico Profissionalizante, no Brasil, tinha pretensão de formar uma força de trabalho técnica especializada para atuação no mercado de trabalho. A demanda por uma mão-de-obra qualificada e especializada para os campos de trabalho era fruto de uma política desenvolvimentista, que invadia o mercado brasileiro, com isso, são criados cursos técnicos profissionalizantes de $2^{\circ}$ grau na esfera do ensino público estadual, como, no caso, da cidade de Natal, na qual existiam três escolas técnicas de comércio, mantidas pelo Governo do Rio Grande do Norte.

As Escolas Técnicas de Comércio, assim conhecidas, naquela época, eram bastante disputadas, como por exemplo, o Centro de Ensino de 2ㅇ Grau Professor Anísio Teixeira1, localizado à Rua Trairi, 480, Bairro Petrópolis, foi

\footnotetext{
${ }^{1}$ Anísio Spínola Teixeira nasceu em Caetité, Sertão da Bahia, em 12 de julho de 1900. Era bacharel em Direito pela Universidade Federal do Rio de Janeiro e exerceu vários cargos na área da educação pública brasileira, tanto como professor da escola normal de Salvador, lecionanda Filosofia e História da Educação, como também diretor do INEP, e escritor de obras sobre educação. Anísio Teixeira fez algumas viagens para o exterior, dentre essas, destaca-se, as duas realizadas para os Estados Unidos em 1927 e 1928, na qual teve 
e ainda é uma instituição mantida pelo governo do Estado do Rio Grande do Norte, gerenciada pela Secretaria de Estado, da Educação e Cultura /SEEC/RN2, tendo sido criada pelo Decreto - Lei № 6.480, no dia 18 de Setembro de 1974 - Portaria de funcionamento № 282/76, de 16/12/1976 Diário Oficial № 3.907 .

De acordo com o Projeto Político Pedagógico (PPP) da escola, sua história teve início com a missão de formar alunos para o mercado de trabalho através do ensino profissionalizante de qualidade, sintonizada com a demanda empresarial e em consonância com os conhecimentos já adquiridos pelos estudantes, desenvolvendo competências e habilidades para 0 exercício da cidadania, pela oferta de cursos de Assistente em Administração e Técnico em Contabilidade.

A Instituição foi fundada com o nome de Centro de Ensino de $2^{\circ}$ Grau Professor Anísio Teixeira em 1973, tendo como preocupação exclusiva a formação técnico-profissional e ênfase nas técnicas básicas; o saber-fazer suficiente para uma determinada profissão, sem maiores aprofundamentos no conhecimento. O seu primeiro ano de funcionamento foi no prédio do Colégio Atheneu Norteriograndense, porém, no ano seguinte, passou a funcionar à Rua Trairi.

Antes da sua criação, na estrutura física funcionou o Jardim Modelo de Natal, a Escola de Aplicação, extensão da Escola Normal de Natal para exercer a prática pedagógica; uma Residência Universitária e a Faculdade de Educação da Universidade Federal do Rio Grande do Norte (UFRN).

A localização do prédio do Centro de Ensino de 20 Grau Professor Anísio Teixeira era estratégica, uma vez que ficava próximo das áreas empresariais e comerciais da capital. As outras duas instituições escolares, com cursos técnicos profissionalizantes para o comércio, ficavam localizadas em outros pontos da cidade potiguar, como por exemplo, a Escola Técnica de Comércio, na Cidade Alta, vizinha ao Instituto de Teologia Pastoral de Natal e de frente à casa do historiador Luiz da Câmara Cascudo. A segunda escola técnica, que ofertava habilitação comercial para o trabalho, era a Escola Estadual Professor Francisco Ivo, no bairro das Quintas, circunvizinha do Centro Comercial Popular do Alecrim.

contato com as ideias do filosofo John Dewey. Dados Disponíveis em: <http://www.scielo.br/pdf/es/v21n73/4203.pdf>. Acesso em: 03 de mai. 2018.

${ }^{2}$ Atualmente a instituição escolar Centro de Ensino de 20 Grau Professor Anísio Teixeira, é oficialmente chamada de Escola Estadual Professor Anísio Teixeira, e oferta Ensino Médio Inovador, nos turnos matutino, vespertino e noturno. 


\section{A LEI № 5.692/71}

Mesmo sendo obrigatória a aplicação da Lei № 5.692 de 11 de agosto de 1971, a mesma sofreu resistência por parte de alguns estabelecimentos de ensino de $2^{\circ}$ Grau, principalmente, das escolas privadas. $\mathrm{O}$ que dificultou a implantação por completo, dessa normativa nas escolas públicas, foi à falta de infraestrutura e orientação pedagógica sobre a proposta. Essa ação das escolas públicas de $2^{\circ}$ Grau deu-se em:

Primeiro lugar, porque a concepção curricular que emanava da Lei empobrecia a formação geral do estudante em favor de uma profissionalização instrumental para o "mercado de trabalho", sob a alegação da importância da relação entre teoria e prática para a formação integral do cidadão. (BRASIL, 2007, p.15).

O discurso destacado na citação demonstra que, a Lei № 5.692/1971 apresentava, em seu texto, a intenção de integrar teoria e prática com o objetivo de formar o cidadão de maneira integral. $O$ que diz essa Lei sobre esse tipo de formação? A Lei № 5.692/1971 adverte em seu artigo1ํo que:

O ensino de $1^{\circ}$ e $2^{\circ}$ Graus tem por objetivo geral proporcionar ao educando a formação necessária ao desenvolvimento de suas potencialidades como elemento de auto-realização, qualificação para o trabalho e preparo para o exercício consciente da cidadania. (BRASIL, 1971, p.1).

Percebe-se que o texto da Lei № 5.692/1971 propõe, textualmente, a superação da dualidade entre duas escolas: a que preparava para a vida e a que treinava para o campo do trabalho. No entanto, essa Lei promoveu a união do trabalho intelectual (ciência, tecnologia e humanidades) e trabalho manual, tornando a escola única? Não havendo mais uma escola de habilitação comercial, agrícola ou normal, a escola de $2^{\circ}$ grau alargou as possibilidades de habilitação de técnicos, sob a crença do "milagre brasileiro" 3, no cerne das políticas desenvolvimentistas do governo civil militar.

Estamos diante de uma contradição. Bremer e Kuenzer (2012) advertem sobre o perigo da escola unidirecional, que prepara apenas para o mercado de trabalho e, especificamente, para o operariado nas indústrias:

Não queremos preparar mão-de-obra para a indústria. Queremos preparar o homem. O homem é mente e mãos: portanto se não educo com as mãos ele fica aleijado. É nesse sentido que nossas

\footnotetext{
${ }^{3}$ O período do "milagre econômico brasileiro", assim, ficou tradicionalmente denominado por constituir uma fase em que a economia do País alcançou altos índices de crescimento para parte da população brasileira. Mas que, de certo modo, foi o suficiente para fazer com que Governo organizasse um aparato propagandístico que primou em divulgar que o Brasil estava caminhando em direção ao progresso. Desta forma, "a expressão 'milagre brasileiro' passou a ser usada como sinônimo de BOOM econômico observado desde 1968 - e também como instrumento de propaganda do governo" (PRADO; EARP, 2003, p. 219). Disponível em:
}

http://www.snh2013.anpuh.org/resources/anais/27/1364931647_ARQUIVO_2013ANPUHBrunaLimaeDiorgeAlcenoKonrad.pdf>. Acesso em: 03 de mai. 2018. 
gerações estão saindo da escola todas intelectualistas. Vários fatores da inteligência não se desenvolvem se estiolam porque não (são) cultivados em idade própria, de 14 a 18 anos. Era este o sentido da educação para o trabalho. (BREMER; KUENZER, 2012, p.5).

Lendo as ideias de Bremer e Kuenzer (2012), fica claro, que a Lei № 5.692/1971 afirma que o ensino de $2^{\circ}$ Grau intencionava formar o cidadão para o trabalho e para exercer sua cidadania, mas, na prática, motivou o "treinamento de estudantes" com vistas ao mercado de trabalho (FRIGOTTO, 2010, p. 38). Nesse sentido, os alunos do ensino técnico profissionalizante provinham das classes populares e eram vistos como operários em formação para acrescer um exército de reserva, sendo estes caracterizados por Marx (1868), como um grupo de trabalhadores que vende sua força de trabalho aos donos dos meios de produção, que transforma em mercadorias e, consequentemente, gera a mais-valia.

Nas palavras de Faria Filho (2001):

A teoria da mais-valia é um dos aspectos mais importantes da teoria marxista do valor. É consensual que a mais-valia é aquela parte do valor adicionado no período que é apropriada pela classe capitalista; em outras palavras, ela é a diferença entre o valor produzido pelos trabalhadores e o valor da força de trabalho. (FARIA FILHO, 2001, p. 27).

Observando a teoria de Marx (1868), percebe-se que o capital não se limita apenas a ser reproduzido, pelo contrário, ele está continuamente se multiplicando e se ampliando. O capital possui um poder sobre a classe trabalhadora (proletariado), ou seja, aqueles privados de propriedade. E, enquanto se germina em proporções cada vez maiores, o modo de produção capitalista moderno reproduz assim mesmo, em grande escala, um número sempre crescente, de operários privados de propriedade.

Segundo Marx (O Capital, Tomo 3):

\begin{abstract}
A acumulação do capital não faz mais que reproduzir as relações do capital numa escala mais alargada, com mais capitalistas ou mais grandes capitalistas por um lado, mais assalariados por outro... A acumulação do capital é, então, ao mesmo tempo, aumento do proletariado. (MARX, 1868, p.1).
\end{abstract}

Sobre tal lógica, Marx (1868) explicou que para se produzir uma mesma quantia de produtos, serão necessários cada vez menos operários, isso, graças ao desenvolvimento da máquina e a modernização no campo da agricultura. A questão é que houve um aperfeiçoamento nas indústrias, com a chegada das máquinas, e com o processo de produção de mercadorias, pois se produzia cada vez mais e em menos tempo. Sendo assim, o desenvolvimento da indústria impulsionou e ocasionou um excedente de trabalhadores. Logo, se questiona: $O$ que se fará com o excedente de operários? Cria-se um exército de reserva?

Formar um exército de reserva para a indústria traduz-se para os donos do capital como uma garantia, de que, durante os momentos de 
fragilidade da produção de mercadorias, podem-se pagar baixos valores pelo trabalho e negar os direitos da classe trabalhadora. Para tanto, se confirma em Marx (O Capital, Tomo 3) que:

\begin{abstract}
Quanto mais a riqueza social crescer... mais numerosa é a sobrepopulação comparativamente ao exército de reserva industrial. Quanto mais este exército de reserva aumenta comparativamente ao exército ativo do trabalho e mais massiva é a sobrepopulação permanente, mais estas camadas compartem a sorte de Lázaro e quanto o exército de reserva é mais crescente, mais grande é a pauperização oficial. Esta é a lei geral, absoluta da acumulação capitalista. (MARX, 1868, p.1).
\end{abstract}

Desse modo, a qualificação do filho da classe-que-vive-do-trabalho (termo muito usado na obra, Os Sentidos do Trabalho, de Ricardo Antunes, publicado em 2009), no contexto da Lei № 5.692/1971, conforme o ideal do Ensino Técnico Profissionalizante de $2^{\circ}$ Grau, com intenção de acrescer um exército de reserva para o mercado brasileiro, reforça ainda mais a máxima de que o governo, nesse período histórico, não estava preocupado com a formação sólida do cidadão, até porque o trabalho era destinado para os filhos dos trabalhadores e o ensino técnico profissionalizante tinha uma intenção de terminalidade, ou seja, não queria formar a classe trabalhadora para a continuidade dos estudos no nível superior.

\title{
4 O ENSINO TECNICO PROFISSIONALIZANTE E O TECNICISMO NO CENTRO DE ENSINO DE 2ㅇ GRAU PROFESSOR ANÍSIO TEIXEIRA
}

Ideologicamente, sabe-se que as práticas pedagógicas do ensino técnico profissionalizante de $2^{\circ}$ Grau, consolidada no tecnicismo, reduzia a ação educativa a uma questão técnica, vislumbrando o pleno ajustamento dos propósitos educativos aos pré-requisitos de uma atividade ou ocupação para o mercado de trabalho, reduzindo a educação a um mero instrumento de treinamento.

A concepção de ensino apontada pela legislação educacional da Lei № $5.692 / 1971$ propunha um "pragmatismo pedagógico" 4 , que se tornava perfil das escolas de ensino técnico profissionalizante, como no caso da principal escola desse tipo de formação em Natal, Rio Grande do Norte, durante os anos 1974 a 1985, o Centro de Ensino de $2^{\circ}$ Grau Professor Anísio Teixeira, que, nessa época, formava uma mão-de-obra técnica especializada, totalmente voltada para atender às necessidades do comércio da cidade, com a profissionalização de mão-de-obra nas áreas de Assistente em Administração e de Contabilidade.

\footnotetext{
${ }^{4}$ Para Saviani (2005) significa dizer que na prática não se tem um critério de distinção entre o natural (bem e mal), mas uma utilidade, o que no sentido prático tem-se um grande valor a atividade pela atividade.
} 
Formar estudantes nos cursos técnicos profissionalizantes de $2^{\circ}$ grau, nos anos de 1974 a 1985, na instituição Centro de Ensino de $2^{\circ}$ Grau Professor Anísio Teixeira, consistiu na materialização do pensamento imposto pela Lei № 5.692/1971, visto que, a maioria dos estudantes que ali eram treinados seriam inseridos no mercado de trabalho.

Essa Lei № 5.692/1971, como afirma Germano (2011), também foi uma estratégia do governo, na época, para não investir na ampliação de vagas nas universidades públicas do Brasil. Estrategicamente, a Lei estancava a ida da classe pobre para o ensino superior, uma vez que a classe pobre era encaminhada apenas para o mercado de trabalho e o $2^{\circ}$ grau ganhava status de terminalidade. Esse fato justifica ainda mais o ideal da classe capitalista, que era formar mão-de-obra qualificada e barata para enriquecer os empresários do Brasil. O país se encontrava em pleno processo de industrialização e desenvolvimento econômico, vivia-se historicamente o denominado "Milagre Econômico Brasileiro"5.

Nota-se que a formação do estudante do Centro de Ensino de $2^{\circ}$ Grau Professor Anísio Teixeira apresentava fragilidades teórico-prática e a sua inserção em um curso de nível superior era muito remota, pois o integrante da classe-que-vive-do-trabalho, nesse modelo de escola técnica profissionalizante de $2^{\circ}$ grau, era formado com base no pensamento da tendência tecnicista ou tecnicismo. O objetivo dessa tendência era simplesmente formar o estudante para executar as atividades técnicas, não pensar criticamente, com a finalidade de ocupar, de imediato, um lugar no mercado de trabalho.

Logo, entende-se que existe uma primazia para a dimensão instrumental do processo formativo, uma vez que o fazer prevalece na formação do sujeito, em detrimento das demais dimensões do processo, sejam as dimensões: humana e político-social, afirmam Castro e Carvalho (2001). Essas ideias, tecidas por Castro e Carvalho (2001), reforçam o porquê das práticas pedagógicas do Centro de Ensino de $2^{\circ}$ Grau Professor Anísio Teixeira, nos anos de 1974 a 1985, terem sido permeadas em seu currículo por oficinas de mecanografia e visitas técnicas às empresas e lojas comerciais, visando sempre o treino de técnicas para aplicação nesses espaços.

\footnotetext{
${ }^{5}$ Segundo Lago (2016) durante os anos de 1967 a 1973 o Brasil alcançou taxas médias de crescimento muito elevadas e sem precedentes, que decorreram em parte da política econômica então implementada principalmente sob a direção do Ministro da Fazenda Antônio Delfim Neto, mas também de uma conjuntura econômica internacional muito favorável. Esse período (e por vezes de forma mais restrita os anos 1968-1973) passou a ser conhecido como o do "milagre econômico brasileiro", uma terminologia anteriormente aplicada a fases de rápido crescimento econômico no Japão e em outros países. Esse "milagre econômico" foi também, em certa medida, o desdobramento de diagnósticos e políticas adotados entre 1964 e 1966 por Otávio Gouveia de Bulhões e Roberto de Oliveira Campos, respectivamente ministros da Fazenda e do Planejamento do governo Castelo Branco, e consubstanciados no Programa de Ação Econômica do Governo (PAEG).
} 
No contexto das práticas, não se aceitava jamais o erro dessas técnicas e nem o uso incorreto de equipamentos/máquinas disponíveis nas oficinas e laboratórios. A prática de aquisição de técnicas, durante as aulas, minimizaria os erros do estudante, no momento em que ele fosse submetido às atividades no mercado de trabalho. A concepção de técnica, nesse contexto, ganha um sentido mecanicista, que tem fim em si mesmo.

Quanto ao currículo do Ensino Técnico Profissionalizante de 2ํㅡrau, este era totalmente voltado para as finalidades formativas objetivadas pela política educacional ditatorial, autoritária e que não ensejava uma formação humana integral e participativa do sujeito na sociedade. Em decorrência desse contexto, o currículo gravita numa zona de interesses de grupos autoritários, o currículo aqui refletia os acontecimentos daquela conjuntura. Por não ser atemporal e neutro, ele representa o que se desejava na formação humana. Um currículo de base tecnicista propicia, possivelmente, uma formação fragmentada, descontextualizada e limitada, não possibilitando ao estudante superar a dicotomia saber e fazer.

O currículo, nesse modelo de ensino técnico profissionalizante de $2^{\circ}$ grau, especialmente, no locus de pesquisa, possuía uma carga de disciplinas maior para a técnica e a instrumentalização. No primeiro ano do curso, o estudante tinha contato com os componentes curriculares da base geral ou propedêutica, tais como se expõe no quadro abaixo:

Quadro 1 - Disciplinas Gerais do 2 Grau Técnico Profissionalizante de Assistente de Administração e de Contabilidade

\begin{tabular}{|c|c|}
\hline Disciplinas & Carga Horaria \\
\hline Língua Portuguesa e Literatura Brasileira & 240 \\
\hline Inglês & 120 \\
\hline História & 90 \\
\hline Geografia & 90 \\
\hline Física & 60 \\
\hline Química & 60 \\
\hline Biologia & 90 \\
\hline Matemática & 90 \\
\hline
\end{tabular}




\begin{tabular}{|c|c|}
\hline Desenho & 60 \\
\hline O.S.P.B (Organização Social e Política Brasileira) & 60 \\
\hline Orientação Vocacional & 60 \\
\hline E.M.C (Educação Moral e Cívica) & 60 \\
\hline Programa de Saúde & 30 \\
\hline Educação Artística & 60 \\
\hline Educação Física & 81 \\
\hline Total & 1.251 \\
\hline
\end{tabular}

Fonte: Autoria própria (2016).

As disciplinas de Educação Moral e Cívica e Organização Social e Política Brasileira (OSPB) foram matérias que tiveram grande destaque na ditadura civil/militar brasileira. A esse respeito, Melo e Toledo (2005) nos advertem que a Educação Moral e Cívica já existia nas escolas, desde a década de 1960, no entanto, a disciplina de Organização Social e Política Brasileira (OSPB) foi instituída nos anos de 1970. Qual era o objetivo dessas duas disciplinas em destaque?

De acordo com Melo e Toledo:

[...] objetivo de disciplinarização da força de trabalho para o projeto desenvolvimentista, o que pode ser percebido na recorrência constante ao artigo $1^{0}$ da Lei 5692/71 que estabelecia como objetivo do ensino de $1^{\circ}$ e $2^{\circ}$ Grau a qualificação para o trabalho. Assim, a escola deveria se enquadrar no projeto do Estado Militar de sociedade fundamentado na ideologia do binômio Segurança e Desenvolvimento. (MELO; TOLEDO, 2005, p.3).

Corroboramos as ideias colocadas por Melo e Toledo (2005), pois se percebe que a legislação do período em estudo tinha como marca a transformação das escolas, da hierarquia curricular, tornando-as uma espécie de publicidade, favorecendo o sentimento de nacionalismo e de desenvolvimentismo, aspectos característicos do período da ditadura civil militar.

Além das ideologias contidas nessas duas disciplinas, existia nas práticas pedagógicas o culto à nação e ao civismo, com vistas à tomada de consciência da cultura brasileira, nas suas manifestações mais dinâmicas e de marcha para o desenvolvimento nacional, adverte Azevedo (1979). 
Conforme a coordenadora pedagógica atual do Centro de Ensino de $2^{\circ}$ Grau Professor Anísio Teixeira, na Escola Estadual Professor Anísio Teixeira, havia a disposição de práticas escolares, durante o período de 1974 a 1985, permeadas por uma supervalorização aos símbolos nacionais, ao culto da pátria, da nação e dos heróis nacionais, ou seja, havia uma cultura escolar permeada pelo culto às tradições e aos símbolos pátrios, como concebe Julia (2001).

Essas práticas extravasavam os espaços da sala de aula, eram realizados momentos cívicos, tais como: hasteamento da bandeira do Brasil, cartazes em honra às datas cívicas (Tiradentes, trabalhador, abolição dos escravos, proclamação da republica brasileira, dia da bandeira, dia da independência). Destacam-se, ainda, os desfiles de 7 de setembro, que ocorriam em frente a escola, na Praça Pedro Velho, mais conhecida como Praça Cívica.

As práticas das tradições, conforme Hobsbawm; Ranger (1984), tratase de rituais ou símbolos que visavam inculcar determinados valores e comportamentos, através da repetição em um processo de continuidade em relação ao passado, via de regra, um passado histórico apropriado. O valor dado às práticas cívicas, como por exemplo, as datas e os símbolos nacionais, são marcas "[...] através dos quais um país independente proclama sua identidade e soberania. Por isso, eles fazem juz a um respeito e uma lealdade imediata. Em si já revelam todo o passado, pensamento e toda a cultura de uma nação". (FIRTH, 1973, p.341).

Além dessa cultura das tradições aos símbolos cívicos, havia também a presença das disciplinas de Educação Moral e Cívica e Organização Social e Política Brasileira (OSPB) que dizia da preocupação dos governantes militares pelo desenvolvimento do sentimento patriótico, apenas desprovido de consciência cidadã, visto que se o fosse, pela formação de cidadãos, estes poderiam exercer sua cidadania de maneira democrática e, inclusive, questionar direitos trabalhistas extirpados, bem como, não aceitar a exploração da classe trabalhadora.

A estrutura do currículo também abrigava disciplinas do Curso Técnico em Assistente de Administração e de Contabilidade. No segundo e terceiro ano do curso, conforme a área escolhida, o aluno estudaria disciplinas de instrumentalização como demonstram os quadros 02 e 03 :

Quadro 2 - Disciplinas Técnicas do 2 Grau Técnico Profissionalizante de Assistente de Administração

\begin{tabular}{|c|c|}
\hline Disciplinas & Carga Horaria \\
\hline Matemática Financeira & 90 \\
\hline
\end{tabular}




\begin{tabular}{|c|c|}
\hline Redação e Expressão & 60 \\
\hline Administração e Controle & 240 \\
\hline Contabilidade e Custos & 120 \\
\hline Direito e Legislação & 150 \\
\hline Estatística & 90 \\
\hline Economia e Mercado & 60 \\
\hline O.T.C & 60 \\
\hline P.R.H & 60 \\
\hline Processamento de Dados & 60 \\
\hline Mecanografia & 120 \\
\hline Total & 1.110 \\
\hline
\end{tabular}

Fonte: Autoria própria (2016).

Quadro 3 - Disciplinas Técnicas do 2ํㅡ Grau Técnico Profissionalizante de Técnico em Contabilidade.

\begin{tabular}{|c|c|}
\hline Disciplinas & Carga Horaria \\
\hline Matemática Financeira & 233 \\
\hline Mecanografia & 72 \\
\hline Processamento de Dados & 72 \\
\hline Pécnicas Orçamentarias de Contabilidade & 288 \\
\hline Contabilidade e Custos & 77 \\
\hline Organização Técnica Comercial & 144 \\
\hline Direito e Legislação & \\
\hline
\end{tabular}




\begin{tabular}{|c|c|}
\hline Contabilidade Industrial Agrícola & 72 \\
\hline Redação e Expressão & 74 \\
\hline Análise e Balanço & 92 \\
\hline Estatística & 72 \\
\hline Economia e Mercado & 74 \\
\hline Total & 1.342 \\
\hline
\end{tabular}

Fonte: Autoria própria (2016).

Os Quadros 02 e 03 das disciplinas técnicas demonstram, que o currículo dos Cursos de Assistente em Administração e Contabilidade tinha a finalidade de formar o filho da classe-que-vive-do-trabalho apenas para realizar tarefas ditas técnicas (instrumental). Essas disciplinas não intencionavam o aprofundamento teórico prático desses conhecimentos, nem a integralização entre a ciência, a técnica e as humanidades, muito menos, a união entre teoria e prática.

A proposta de currículo reforçava um tipo específico de formação, ofertada aos filhos dos trabalhadores, nas décadas de 1974 a 1985, especificamente, no locus desta pesquisa: nem formava para o exercício pleno da cidadania e nem para concorrer a um curso de nível superior, nas universidades brasileiras.

Desse modo, o currículo do ensino técnico profissionalizante de $2^{\circ}$ grau possuía uma matriz fragmentada em dois polos de disciplinas, centrado nas características do modelo pedagógico, com destaque no currículo para os fins do ensino tecnicista e para a própria prática pedagógica, alicerçada no ideário politico, econômico e cultural, que influenciou fortemente a educação ofertada aos filhos da classe trabalhadora, cuja preocupação do sistema escolar e governamental era o aperfeiçoamento da técnica para que 0 estudante fizesse uso nas indústrias, no comércio e nas empresas.

$\mathrm{Na}$ verdade, esse modelo de ensino não foi implementado na sua integralidade que era formar o homem para o trabalho e para a ciência, como regia a Lei № 5.692/71, pois não se concebe "pensar num técnico que não tenha sólida formação científica é muito precário para o nível de desenvolvimento das forças produtivas que se avizinham" (GERMANO, 2011, p.172), mas, esse era o discurso realizado pelo modelo pedagógico tecnicista ou do tecnicismo.

Freire (1996) apresentou severas críticas ao tecnicismo no Brasil, conceituando-o como sendo uma formação limitadora, quando se preocupa 
apenas com o treino técnico científico do discente. A concepção de Freire (1996) amplia essa perspectiva e diz que a formação dos sujeitos deve ser para a vida e ir além da preparação técnica e científica, inclusive, não ser uma educação bancária, aquela em que o professor deposita inúmeras informações no cérebro do estudante e este só faz memorizar para usar apenas em uma atividade fim, não servindo para aplicar nas várias situações da vida social.

Quando Freire (1996) adverte que a formação do estudante deveria ir além da instrução técnica e científica, ele defendia que o discente deveria ser formado para lidar com os vários aspectos da vida, do mundo do trabalho, da ciência, da cultura e da tecnologia. Com base nessas ideias, levanta-se a defesa da proposta de ensino pautada no ideal de currículo integrado, a fim de fornecer uma sólida formação científica, tecnológica, cultural e ética, assim como advoga Machado (2010, p. 92):

\begin{abstract}
Currículos integrados são oportunidades riquíssimas para explorar as potencialidades multidimensionais da educação, para superar a visão utilitarista do ensino, para desenvolver as capacidades de pensar, sentir e agir dos alunos, para realizar o objetivo da educação integral.
\end{abstract}

Depois dessa definição, compreende-se o conceito de currículo integrado. Na época do tecnicismo, o pensamento educacional ou o modelo de ensino técnico de $2^{\circ}$ grau ofertado, conforme a Lei № 5.692/1971, não era a mesma proposta defendida por Machado (2010), até porque o formato de currículo integrado proposto pela autora é, de certa maneira, uma possibilidade de integração entre as finalidades e os objetivos da escola à prática pedagógica, tornando-o efetivamente concreto e que, em hipótese alguma, se destina a treinar ou adestrar o estudante.

Então, fica evidente que a proposta pedagógica da tendência tecnicista, que vigorava nos anos 1974 a 1985, na prática, foi unilateral, apenas se preocupava com a formação técnica, divergindo da proposta do currículo integrado, apresentada por Machado (2010). Visto que, a autora busca considerar as muitas dimensões da vida dos alunos e das práticas sociais em que estão incluídos, tentando entendê-los como sujeitos implicados no seu próprio processo de formação, oportunidade para a libertação, transformando-os em seres críticos.

A formação educacional integradora é aquela em que os seus objetivos se destinam a tornar interdependentes áreas diversificadas de conhecimentos, sendo assim, a escola formaria o educando para a vida, permeando os espaços do mundo do trabalho e do fazer científico. Diante da proposição, questiona-se se o ensino técnico profissionalizante de $2^{\circ}$ grau, regido pela Lei № 5.692/1971, oportunizou esse tipo de integração, visto porque seus fins voltavam-se apenas para a formação técnica do estudante.

A proposta do ensino de $2^{\circ}$ grau profissionalizante objetivava formar mão-de-obra rápida e barata, por isso, estava distante de querer unir os 
conhecimentos do currículo propedêutico e instrumental, rompendo-se parcialmente com a escola que dividia o ensino para os ricos (propedêutico) e para os pobres (instrumental).

A respeito da problemática, Moura (2010) destaca que não basta apenas dar acesso à Educação Básica à classe popular, mas é bom que se garanta a aquisição de conhecimentos para esse povo. Quando se fala em efetivar a garantia da aprendizagem da classe menos favorecida brasileira, significa fazer com que essa classe integre cidadãos críticos, de modo que tenham consciência que são detentores de direitos e de deveres e não somente reprodutores desses ideais.

A classe trabalhadora precisa compreender que não pode se limitar apenas à Educação Básica, mas deve lutar pela garantia da aquisição de amplo conhecimento e formação sólida, conforme Moura (2010). Que as oportunidades de educação não sejam para a opressão, mas para a libertação do homem, ou seja, o trabalhador precisa de uma educação emancipadora, como advoga Freire (1996).

As praticas pedagógicas do contexto tecnicista empreendidas no Centro de Ensino de 2ำ Grau Professor Anísio Teixeira em grande parte aglutinaram conhecimentos vinculados ao mercado do trabalho e tentavam repassar os fundamentos da vida cidadã, mas será que as práticas pedagógicas dessa instituição potencializavam os sujeitos para emancipação das classes populares, tornando-os autores da sua própria história, uma história de lutas e conquistas sociais?

\section{CONSIDERAÇÕES FINAIS}

Chegou-se a conclusão com essa pesquisa, que o Centro de Ensino de $2^{\circ}$ Grau Professor Anísio Teixeira, era uma das principais escolas técnicas profissionalizantes de referência na cidade de Natal-RN, seu papel era treinar os estudantes para o mercado de trabalho, nas áreas comerciais, em cursos de Assistente em Administração e Contabilidade, nos anos de 1974 a 1985, o que conforme análise cumpria em grande medida o que preconizava a Lei № $5.692 / 1971$.

Historicamente as práticas pedagógicas do Centro de Ensino de $2^{\circ}$ Grau Professor Anísio Teixeira era de fato o treinamento dos estudantes para atuar no comércio e empresas da capital do Rio Grande do Norte, é tanto que tinham uma carga horária de disciplinas técnicas muito maior do que as da base comum. Além disso, faziam estágios nas empresas e lojas comerciais, sendo boa parte deles inseridos no mercado de trabalho.

Enfim, o ensino técnico profissionalizante no Rio Grande do Norte, nos anos de 1974 a 1985, tem no Centro de Ensino de 2ํGrau Professor Anísio Teixeira um espaço histórico e pedagógico demarcado, posto que esse 
aplicou em sua integralidade a legislação que impunha a todos os estabelecimentos de ensino de $2^{\circ}$ grau, a tornar-se ensino técnico.

\section{REFERÊNCIAS}

ANTUNES, R. Os Sentidos do trabalho: ensaio sobre a afirmação e a negação do trabalho. 2. ed. São Paulo: Boitempo, 2009.

BRASIL. Lei n. 5.692, de 11 de Agosto de 1971. Diretrizes e Bases da Educação Nacional. Diário Oficial da República Federativa do Brasil. Brasília, 1971. Disponível em:<http://www.planalto.gov.br/ccivil_03/leis/15692.htm>. Acesso em: 24 de mai. 2015.

BRASIL. Lei n. 9.394, de 20 de Dezembro de 1996. Diretrizes e Bases da Educação Nacional. Diário Oficial da República Federativa do Brasil. Brasília, 1996. Disponível em: http://www.planalto.gov.br/ccivil_03/leis/19394.htm>. Acesso em: 24 de mai. 2015.

BRASIL. Ministério da Educação. Educação Profissional Técnica de Nível Médio Integrada ao Ensino Médio: Documento Base. Brasília: MEC, 2007. Disponível em:< http://portal.mec.gov.br/setec/arquivos/pdf/documento_base.pdf>. Acesso em: 09 de jun. 2016

BREMER, M. A. de S.; KUENZER, A. Z. ENSINO MÉDIO INTEGRADO: UMA HISTÓRIA DE CONTRADIÇÕES. IX ANPED SUL. Seminário de Pesquisa em Educação da Região Sul. 2012. Disponível em:<http://www.ucs.br/etc/conferencias/index.php/anpedsul/9anpedsul/paper/ viewFile/2217/208>. Acesso em 12 de mai. 2015.

CASTRO, A. D. de; CARVALHO, A. M. P. de. Ensinar a ensinar: didática para a escola fundamental e média. São Paulo: Pioneira, 2001.

CHERVEL, A. História das disciplinas escolares: reflexões sobre um campo de pesquisa. Teoria e Educação, Porto Alegre, n.1, p.177-229, 1990. CIAVATTA, M.; RAMOS, M. A "era das diretrizes": a disputa pelo projeto de educação dos mais pobres. Revista Brasileira de Educação [online]. 2012, vol.17, n.49, pp. 11-37. ISSN 1413-2478. Disponível em: <http://dx.doi.org/10.1590/S1413-24782012000100002>. Acesso em: 20 de abr. 2015.

A formação integral: a escola e o trabalho como lugares de memória e de identidade. In: FRIGOTTO, G.; CIAVATTA, M.; RAMOS, M. N. Ensino médio integrado: comparação e contradições. São Paulo: Cortez, 2005, p. 85-105.

CUNHA, L. A. O ensino profissional na irradiação do industrialismo. São Paulo: Unesp, 2005. 
ENGELS, F. O capital de Karl Marx: 13 de março de 1868. Disponível em: https://www.marxists.org/portugues/marx/1868/03/28-ga.htm>. Acesso em: 19 de mar. 2016.

FAHEINA, E. F. A. A racionalização do trabalho pedagógico e o uso de recursos audiovisuais na educação: um olhar sobre a pedagogia tecnicista no Brasil. Revista Histedbr On-line. Campinas, n.43, p.92-102, set. 2011.

FARIA FILHO, L. M. et al. A cultura escolar como categoria de análise e como campo de investigação na história da educação brasileira. Revista Educação e Pesquisa. São Paulo, v. 30, n. 1, p.139-159, jan./abr. 2004.

FIRTH, R. Symbols, public and private. Londres: Routledge Revivals, 1973.

FREIRE, P. Pedagogia da Autonomia: saberes necessários à prática educativa. São Paulo: Paz e Terra, 1996.

FREIRE, P. ; SHOR, I. Medo e ousadia: o cotidiano do professor. 10. ed. São Paulo: Paz e Terra, 1986.

FRIGOTTO, G. A relação da educação profissional e tecnológica com a universalização da educação básica. In: MOLL, Jaqueline. Educação Profissional e Tecnológica no Brasil Contemporâneo: desafios, tensões e possibilidades. Porto Alegre: Artmed, 2010.

GERMANO, J. W. Estado militar e educação no Brasil (1964-1985). 5. ed. São Paulo: Cortez, 2011.

HOBSBAWM, E. ; RANGER, T. A invenção das tradições. São Paulo: Paz e Terra, 1984.

JULIA, D. A cultura escolar como objeto histórico. Revista Brasileira de História da Educação, Campinas, n.1, p.09-43, jan./jun. 2001.

LAGO, L. A. C. do. Milagre econômico brasileiro. Disponível em:< http://www.fgv.br/cpdoc/acervo/dicionarios/verbete-tematico/milagreeconomico-brasileiro>. Acesso em: 24 de jul. 2016.

LIMA, B.; KONRAD, D. A. O "milagre econômico brasileiro" e sua relação com a criação do distrito industrial de Santa Maria - RS. Disponível em: < http://www.snh2013.anpuh.org/resources/anais/27/1364931647_ARQUIVO_2 013ANPUH-BrunaLimaeDiorgeAlcenoKonrad.pdf>. Acesso em 03 de mai. 2018.

MACHADO, L. Ensino médio e técnico com currículos integrados: proposta de ação didática para uma relação não fantasiosa. In: MOLL, Jaqueline. Educação profissional e tecnológica no Brasil contemporâneo: desafios, tensões e possibilidades. Porto Alegre: Artmed, 2010, p. 80-95.

MAGALHÃES, J. Contributo para a história das instituições educativas: entre a memória e o arquivo. Braga: Universidade do Minho. 1996. 
Tecendo nexos: história das instituições educativas. Bragança Paulista-SP: Editora Universitária São Francisco, 2004.

MANACORDA, M. A. História da educação: da antiguidade aos novos dias. 10. ed. São Paulo: Cortez, 2002.

MELO, F. E. de; TOLEDO, E. T. O ensino de estudos sociais, ECM e OSPB e a ressignificação da cultura cívica nacional nas práticas escolares em escolas de Fortaleza durante o regime militar. ANPUH XXIII SIMPÓSIO NACIONAL DE HISTÓRIA - Londrina, 2005. Disponível em:< http://anais.anpuh.org/wpcontent/uploads/mp/pdf/ANPUH.S23.0393.pdf>. Acesso em: 25 de mar. 2016.

MOURA, D. H. Ensino médio e educação profissional: dualidade histórica e possibilidade de integração. In: MOLL, Jaqueline. Educação profissional e tecnológica no Brasil contemporâneo: desafios, tensões e possibilidades. Porto Alegre: Artmed, 2010, p. 58-79.

NETO, N. N. G. Exército industrial de reserva: conceito e mensuração. 2013. 126f. Dissertação (Mestrado em Desenvolvimento Econômico) Universidade Federal do Paraná. Setor de Ciências Sociais Aplicada. Programa de Pós-graduação em Desenvolvimento Econômico, Curitiba, 2013.

NOSELLA, P. ; BUFFA, E. Instituições escolares: por que e como pesquisar. Campinas-SP: Alínea, 2010.

NUNES, C. Anísio Teixeira. Entre nós: a defesa da educação como direito de todos. Disponível em: < http://www.scielo.br/pdf/es/v21n73/4203.pdf>. Acesso em: 03 de mai. 2018.

PROJETO Político Pedagógico da Escola Estadual Professor Anísio Teixeira. Natal: SEECD, 2015. (Digitado).

RAMOS, M. Ensino médio integrado: ciência, trabalho e cultura na relação entre educação profissional e educação técnica. In: MOLL, Jaqueline. Educação profissional e tecnológica no Brasil contemporâneo: desafios, tensões e possibilidades. Porto Alegre: Artmed, 2010, p. 42-57.

SAVIANI, D. As concepções pedagógicas na história da educação brasileira. Campinas, $2005 . \quad$ Disponível em: <http://www.histedbr.fe.unicamp.br/navegando/artigos_pdf/Dermeval_Saviani _artigo.pdf>. Acesso em: 19 de mar. 2016.

SILVA, C. M. C. de S. História das práticas pedagógicas e cultura escolar do Colégio Salesiano Santa Teresa, Corumbá-MS (1972-1987). 2009. 179f. Tese (Doutorado em Educação) - Universidade Estadual de Campinas. Faculdade de Educação, Campinas, 2009.

SILVA, L. P. L. de O. e. A legislação educacional: estabelecendo diferenças entre a lei da reforma do ensino de $1^{\circ}$ e $2^{\circ}$ graus $n^{\circ} .5 .692 / 71$ e a lei de diretrizes e bases da educação nacional no. 9.394/96. 2007. $145 f$. 
Dissertação (Mestrado em Educação) - Universidade Metodista de Piracicaba. Faculdade de Ciências Humanas. Programa de Pós-Graduação em Educação, Piracicaba-SP, 2007.

SILVA, M. da G. de S. Escola para os filhos dos outros: trajetória histórica da Escola Industrial de Natal (1942-1968). 2012. 225f. Tese (Doutorado em Educação) - Universidade Federal do Rio Grande do Norte. Centro de Educação. Programa de Pós-graduação em Educação, Natal, 2012.

SKINNER, B. F. Tecnologia do ensino. Tradução de Rodolpho Azzi. São Paulo: Herder, Ed. da Universidade São Paulo, 1972.

Sobre o behaviorismo. Tradução de M. P. Villa lobos. São Paulo: Cultrix, 2006. (Trabalho original publicado em 1974). 